\title{
Quantification of carbohydrates in fruit juices using FTIR spectroscopy and multivariate analysis
}

\author{
Loredana F. Leopold ${ }^{\mathrm{a}}$, Nicolae Leopold ${ }^{\mathrm{b}}$, Horst-A. Diehl ${ }^{\mathrm{c}}$ and Carmen Socaciu ${ }^{\mathrm{a}, *}$ \\ ${ }^{\text {a }}$ Faculty of Agriculture, Department of Chemistry and Biochemistry, University of Agricultural \\ Sciences and Veterinary Medicine, Cluj-Napoca, Romania \\ ${ }^{\mathrm{b}}$ Faculty of Physics, Babeş-Bolyai University, Cluj-Napoca, Romania \\ ${ }^{\mathrm{c}}$ Institut für Biophysik, Universität Bremen, Bremen, Germany
}

\begin{abstract}
A combination of Fourier-transform infrared spectroscopy (FTIR) and multivariate statistics was applied as screening tool for the quantitative determination of carbohydrates, such as glucose, fructose and sucrose, in 28 processed commercial fruit juices and 5 genuine juices obtained from squeezed fruits. A number of 13 mixtures of glucose, fructose and sucrose standard solutions were prepared at different concentrations, scanned by attenuated total reflectance (ATR) FTIR spectroscopy and analyzed in the 900 and $1400 \mathrm{~cm}^{-1}$ spectral range. Principal component analysis (PCA) of the standard carbohydrate solutions enabled a better understanding of the main sources of variability affecting the FTIR spectra. Also, PCA enabled the grouping of apple, orange and peach juices. Calibration models for each carbohydrate, using partial least squares (PLS) regression were developed and used for prediction purposes. Cross-validation procedures indicated correlations of 0.88, 0.92 and 0.98 for glucose, fructose and sucrose, respectively, between HPLC measured values and FTIR first derivative spectra estimates. Carbohydrates in the expected concentration ranges were found for most of the pure fruit labelled juices. The samples with 4$50 \%$ pure fruit juice content showed discrepancies from average concentration values of authentic juices, mainly a high sucrose concentration can flag sucrose addition to maintain the juice sweetness intensity. The present results confirmed the efficiency of FTIR spectroscopy, in combination with multivariate statistics, as a rapid, reliable and cost-effective tool for routine monitoring of multiple constituents in fruit juices, as quality indicators.
\end{abstract}

Keywords: Glucose, fructose, sucrose, fruit juice, FTIR, PCA, PLS

\section{Introduction}

Evaluation of fruit juice quality and authenticity is an important applied research area, with relevant impact in industry, food science and consumer protection. Rapid and cost effective methods of carbohydrate determination in fruit juices are of high importance, since unscrupulous companies, manufacturers or traders seek substantial benefits using adulterated juices to gain market advantages over honest competitors, using cheaper ingredients (fruit juices, sugar and syrups) and/or false label indications for consumers.

Discrepancies in component ratios can be used to flag suspicious fruit juices, glucose, fructose and sucrose being main authenticity markers [13].

\footnotetext{
* Corresponding author: Carmen Socaciu, Faculty of Agriculture, Department of Chemistry and Biochemistry, University of Agricultural Sciences and Veterinary Medicine, Calea Mănăştur 3-5, 400372 Cluj-Napoca, Romania. Tel.: +40 264 596384; Fax: +40 264 593792; E-mail: casocaciu@ usamvcluj.ro.
} 
In the case of commercial juices, some additives may significantly affect $\mathrm{pH}$ and total carbohydrate content, reducing the ability to obtain information on their quality (e.g., ripening stage of the source fruits). Often, $\mathrm{pH}$ regulators (e.g., citric acid), sucrose or other sweeteners are added so that $\mathrm{pH}$ and total carbohydrate content are no longer a reflection of the ripening stage of the source fruit. In these cases, evaluation of individual carbohydrate contents may still be used as an indicator of ripening stage [16].

Traditionally, carbohydrate content of foods (particularly in juices and beverages) are estimated based on refractive index measurements or volumetric procedures, which provide information about the total carbohydrate content. To quantify each carbohydrate, several methods can be employed, including enzymatic analysis and chromatographic methods $[4,6,7]$.

However, chromatographic techniques (GC, HPLC), successfully used to evaluate fruit juice authenticity by oligosaccharide profiling [24], although accurate, are time consuming, expensive and difficult to implement in an on-line setting.

Other spectroscopic approaches, such as nuclear magnetic resonance (NMR) spectroscopy, considering the entire sample composition, may also be applied for authenticity studies and food composition profiling [19].

FTIR spectroscopy became an alternative technique for the analysis of carbohydrates in food samples, being cost-effective and potentially more rapid than the above mentioned methods. FTIR spectroscopy can potentially give information about the proportions of the three main carbohydrates (glucose, fructose and sucrose) and their variation with ripening. FTIR has been increasingly used, often coupled with chemometrics, to study a range of food samples $[1,5,7,16,20,25,28]$ and particularly to study liquid foods such as juices and soft drinks $[2,3,11,13,15,17,18,21,26]$. For quantification of carbohydrates in several fruit juices and soft drinks, the use of a reduced calibration set, comprising only eight ternary mixtures of glucose, fructose, and sucrose at two concentration levels, has been previously proposed $[11,26]$.

In a recent study we predicted the total antioxidant capacity of fruit juices by using FTIR-PLS, a correlation of 0.97 between measured and predicted values being found [23]. In the present study, FTIR spectroscopy, combined with PLS regression, as multicomponent analysis method, is used, in order to quantify simultaneously the glucose, fructose and sucrose content in 33 samples of pure, genuine and commercial juices, comparatively. Standardized mixtures of these three carbohydrates are used for calibration.

\section{Materials and methods}

\subsection{Samples}

A number of 28 soft drink juices were supplied from supermarkets. A number of 5 genuine (authentic) fruit juices (apple, peach, orange, pineapple and pear) were obtained by squeezing the corresponding fruits obtained from supermarkets. The 33 juice samples with pure fruit juice content between 4 and $100 \%$ are described in Table 1, according to the package label.

A total of 13 pure carbohydrate solutions (standard mixtures in double distilled water) with different concentrations of glucose $(0.5-4.0 \mathrm{~g} / 100 \mathrm{ml})$, fructose $(0.5-14.0 \mathrm{~g} / 100 \mathrm{ml})$ and sucrose $(0.5-$ $8.0 \mathrm{~g} / 100 \mathrm{ml}$ ) were prepared, covering the concentration ranges representative for natural juice samples, and used for the development of the calibration models. 
Table 1

Fruit juice samples notation and short description

\begin{tabular}{|c|c|c|c|c|c|}
\hline No. & Sample & Description & No. & Sample & Description \\
\hline 1 & Ap1_100\% & Apple juice $100 \%$ & 18 & Or_G & $\begin{array}{l}\text { Genuine orange juice } \\
\text { (squeezed orange) }\end{array}$ \\
\hline 2 & Ap2_100\% & Apple juice $100 \%$ & 19 & Pc1_50\% & Peach juice $50 \%$ \\
\hline 3 & Ap3_100\% & Apple juice $100 \%$ & 20 & Pc2_50\% & Peach juice $50 \%$ \\
\hline 4 & Ap4_100\% & Apple juice $100 \%$ & 21 & Pc3_46\% & Peach juice $46 \%$ \\
\hline 5 & Ap5_40\% & Green apple juice $40 \%$ & 22 & Pc4_45\% & Peach juice $45 \%$ \\
\hline 6 & Ap_G & $\begin{array}{l}\text { Genuine apple juice } \\
\text { (squeezed Jonagold apple) }\end{array}$ & 23 & Pc5_10\% & Peach juice $10 \%$ \\
\hline 7 & Ac_50\% & Apricots juice $50 \%$ & 24 & Pc_G & $\begin{array}{l}\text { Genuine peach juice } \\
\text { (squeezed peach fruit) }\end{array}$ \\
\hline 8 & Ch_15\% & Cherry juice $15 \%$ & 25 & Pi1_100\% & Pineapple juice $100 \%$ \\
\hline 9 & Or1_100\% & Orange juice $100 \%$ & 26 & Pi2_50\% & Pineapple juice 50\% \\
\hline 10 & Or2_100\% & Orange juice $100 \%$ & 27 & Pi_G & $\begin{array}{l}\text { Genuine pineapple juice } \\
\text { (squeezed pineapple) }\end{array}$ \\
\hline 11 & Or3_100\% & Orange juice $100 \%$ & 28 & Pr1_50\% & Pear juice $50 \%$ \\
\hline 12 & Or4_100\% & Orange juice $100 \%$ & 29 & Pr2_50\% & Pear juice $50 \%$ \\
\hline 13 & Or5_100\% & Orange juice $100 \%$ & 30 & Pr3_50\% & Pear juice $50 \%$ \\
\hline 14 & Or6_100\% & Orange juice $100 \%$ & 31 & $\operatorname{Pr} 4 \_30 \%$ & Pear juice $30 \%$ \\
\hline 15 & Or7_100\% & Orange juice $100 \%$ & 32 & Pr_G & $\begin{array}{l}\text { Genuine pear juice } \\
\text { (squeezed Packham pear) }\end{array}$ \\
\hline 16 & Or8_100\% & Orange juice $100 \%$ & 33 & To_100\% & Tomato juice $100 \%$ \\
\hline 17 & Or9_4\% & Orange juice $4 \%$ & & & \\
\hline
\end{tabular}

\subsection{FTIR spectroscopy}

The mid-IR (MIR) absorbance spectra $\left(600-3500 \mathrm{~cm}^{-1}\right)$ were recorded using a FTIR spectrometer (IR-Prestige, Shimadzu Europa GmbH, Duisburg, Germany) equipped with a deuterated L-alanine doped triglycene sulphate (DLATGS) detector working at room temperature. The spectral resolution was $4 \mathrm{~cm}^{-1}$ and 128 scans were accumulated for each spectrum. The sampling station was equipped with a horizontal attenuated total reflectance (ATR) accessory with multiple reflections (10 reflections) (PIKE Technologies, Madison, WI, USA). As reference, the background spectrum of air was collected. The juice samples were measured without any preparation, directly on the ZnSe ATR crystal. Between measurements the ATR crystal was carefully cleaned using distilled water and dried.

\subsection{HPLC analysis}

Carbohydrates were separated and quantified using a Shimadzu chromatograph, equipped with a binary pump delivery system, autosampler and refractive index detector RID-10A. The chromatographic separation of the compounds was achieved by using a C18 $(250 \times 4.6 \mathrm{~mm})$ Altima Amino modified column. Elution was performed by $30^{\circ} \mathrm{C}$, with an isocratic solvent, acetonitrile: water $(80: 20, \mathrm{v} / \mathrm{v})$ at a constant flow of $1.3 \mathrm{ml} / \mathrm{min}$. Carbohydrates were identified by comparing the retention time with known standard solutions. 


\subsection{Principal components analysis (PCA) and partial least squares (PLS) regression}

As described in the literature, PCA is used to find the main variability sources in a data set and the relationship between/within objects and variables [10,22]. PLS is used to model the relationship between a set of predictor variables $X$ ( $n$ objects $k$ variables) and a set of response variables $Y$ ( $n$ objects $m$ responses) [12]. In this study there is only one response (carbohydrate concentration), therefore $Y$ has ( $n$ objects 1 response) dimensions. Based on the PLS model, the carbohydrate contents were predicted with prediction errors defined as root mean square error of prediction (RMSEP):

$$
R M S E P=\sqrt{\frac{\sum_{i=1}^{N}\left(y_{i}-\hat{y}_{i}\right)^{2}}{N}},
$$

where $N=$ number of samples, $y_{i}=$ actual concentration and $\hat{y}_{i}=$ predicted concentration. $R M S E P$ can be interpreted as the average prediction error, expressed in the same units as the original response values $(\mathrm{g} / 100 \mathrm{ml}$ in this study).

The Unscrambler software (CAMO, Norway) was used for multicomponent analysis by using the PCA and PLS routine analysis. Best RMSEP were obtained by using the first-derivative transformed spectra. The derivatives were calculated based on the Savitzky-Golay procedure, averaging left side and right side 4 points and using a 2nd degree polynomial.

Full cross validation was chosen in the model computation. With full cross validation, the same samples are used both for model estimation and testing. One sample is left out from the calibration data set and treated as an unknown sample, the model being calibrated on the remaining data points. Then the value for the left-out sample is predicted and the prediction residuals are computed. The process is repeated with another subset of the calibration set, and so on until every object has been left out once; then all prediction residuals are combined to compute the validation residual variance and RMSEP.

The calibration models were developed using the first-derivative spectra of the 13 pure standard solutions of glucose, fructose and sucrose. The carbohydrates fingerprint region in the spectral range 900$1400 \mathrm{~cm}^{-1}$ was used for calibration and prediction purposes. To avoid overfitting, the number of principal components (PCs) were correlated with the increasing of the explained validation variance.

\section{Results and discussion}

\subsection{Spectral fingerprint of carbohydrates}

In order to fingerprint the carbohydrate region, with specific glucose, fructose and sucrose absorptions, the ATR-FTIR absorption spectra of individual solutions of glucose $(4 \mathrm{~g} / 100 \mathrm{ml})$, fructose $(14 \mathrm{~g} / 100 \mathrm{ml})$ and sucrose $(8 \mathrm{~g} / 100 \mathrm{ml})$ were recorded, as presented in Fig. 1a. Glucose, fructose and sucrose show intense characteristic bands in the fingerprint region $\left(900-1400 \mathrm{~cm}^{-1}\right)$ of the mid-infrared spectral range (Fig. 1a). It is clear from the plot that when the three carbohydrates are present in the same solution, strong band overlap occurs and seriously hinders individual carbohydrate quantification.

Several marker bands of glucose, fructose and sucrose were identified in the spectral range between 900 and $1400 \mathrm{~cm}^{-1}$. The bands in the region $900-1153 \mathrm{~cm}^{-1}$ are assigned to $\mathrm{C}-\mathrm{O}$ and $\mathrm{C}-\mathrm{C}$ stretching modes, while those in the $1400-1199 \mathrm{~cm}^{-1}$ region are due to $\mathrm{O}-\mathrm{C}-\mathrm{H}, \mathrm{C}-\mathrm{C}-\mathrm{H}$ and $\mathrm{C}-\mathrm{O}-\mathrm{H}$ bending vibrational modes of the carbohydrates [15]. 


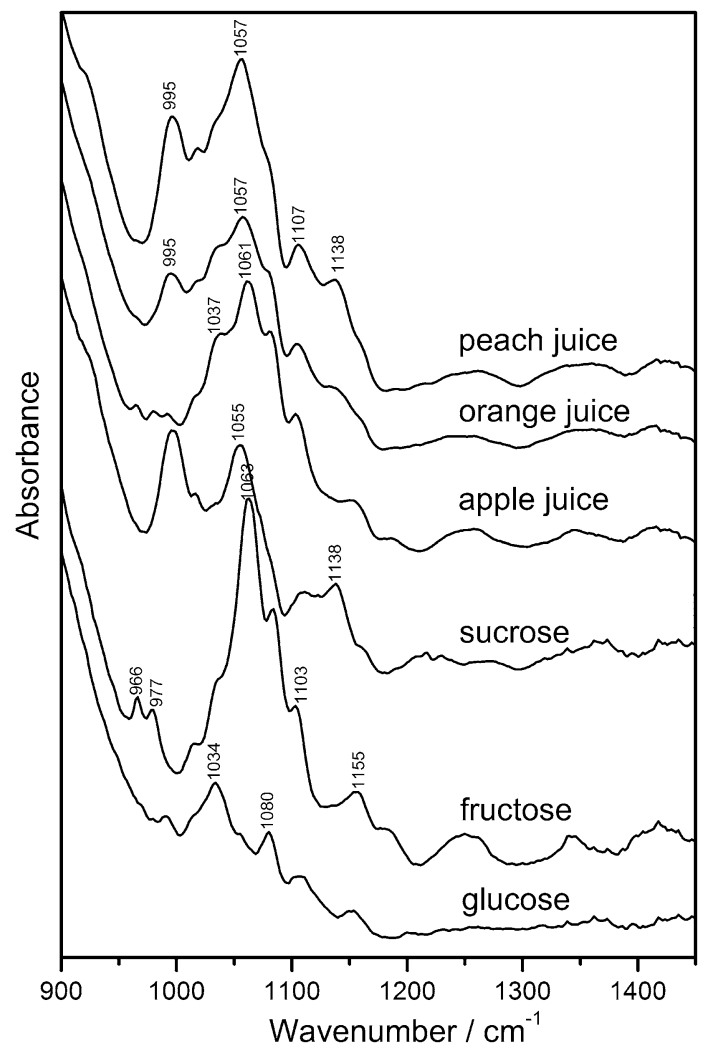

(a)

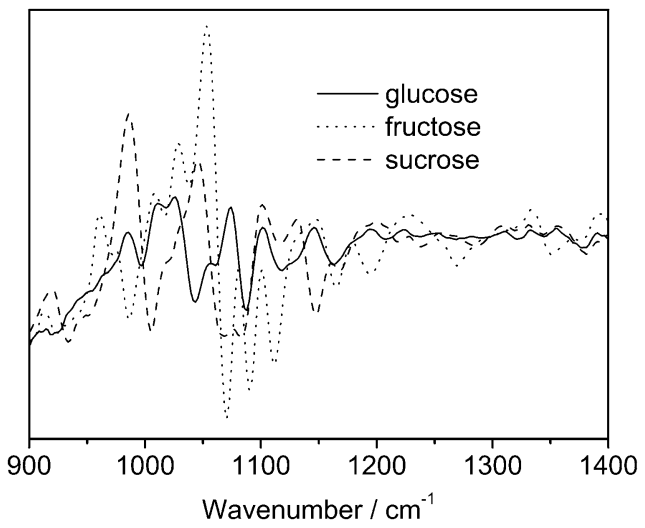

(b)

Fig. 1. (a) FTIR spectra of glucose $(4 \mathrm{~g} / 100 \mathrm{ml})$, fructose $(14 \mathrm{~g} / 100 \mathrm{ml})$ and sucrose $(8 \mathrm{~g} / 100 \mathrm{ml})$ standards in parallel with apple, orange and peach commercial juices (samples Ap1, Or1 and Pc1 - described in Table 1) spectra. (b) First derivative FTIR spectra of glucose, fructose and sucrose standards presented above.

A higher sucrose level in the peach and orange juice as in the apple juice can be observed by visual inspection of the spectra in Fig. 1a, as revealed by the intense marker band of sucrose at $995 \mathrm{~cm}^{-1}$. Direct quantification based on this band will be not accurate, due to overlapping bands from glucose and fructose in this region. Generally, an assessment of individual carbohydrates content in fruit juices, based on visual analysis of the FTIR spectra, is difficult or even speculative, considering the overlapping of several marker bands. Thus, multivariate statistical methods represent valuable tools for multicomponent analysis.

\subsection{Principal component analysis $(P C A)$}

For a better understanding of the main sources of variability affecting the FTIR spectra of the employed standard carbohydrate solutions (glucose, fructose and sucrose mixtures), PCA was performed on the corresponding first derivative spectra in the $900-1400 \mathrm{~cm}^{-1}$ region (Fig. 1b). Figure 2 shows the scores scatter plot of the first two principal components (PCs), which together account $93 \%$ of the total variability present in the spectra.

The obtained scores plot shows that the samples are distributed along concentration gradients, according to their carbohydrate composition, in the surface of a triangle. As expected, the three individual 


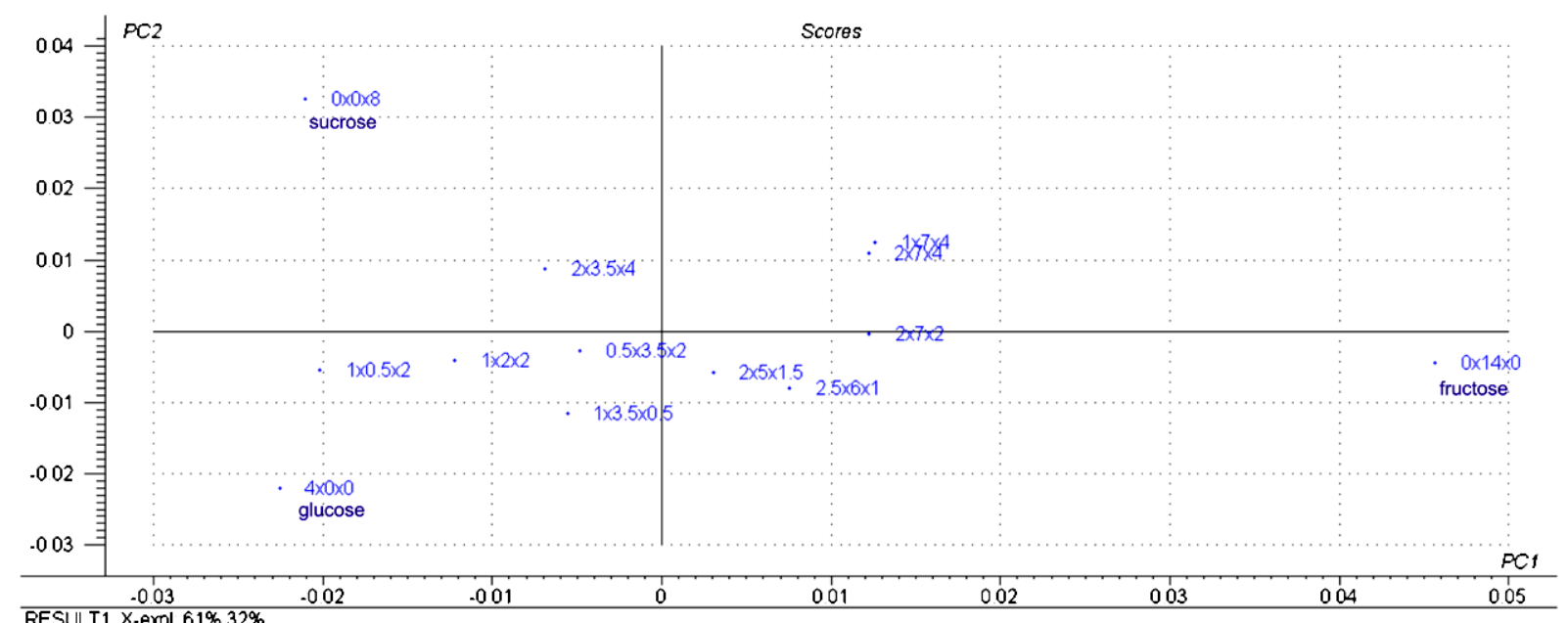

Fig. 2. Scores scatter plot of the first two principal components, PC1 and PC2, obtained in the PCA analysis of the 13 standard carbohydrate solutions, using their first derivative FTIR spectra. The concentration $(\mathrm{g} / 100 \mathrm{ml})$ of each carbohydrate is coded as $\mathrm{g} \times \mathrm{f} \times \mathrm{s}$, where $\mathrm{g}, \mathrm{f}$ and $\mathrm{s}$ are abbreviations for glucose, fructose and sucrose, respectively. (Colors are visible in the online version of the article; http://dx.doi.org/10.3233/SPE-2011-0529.)

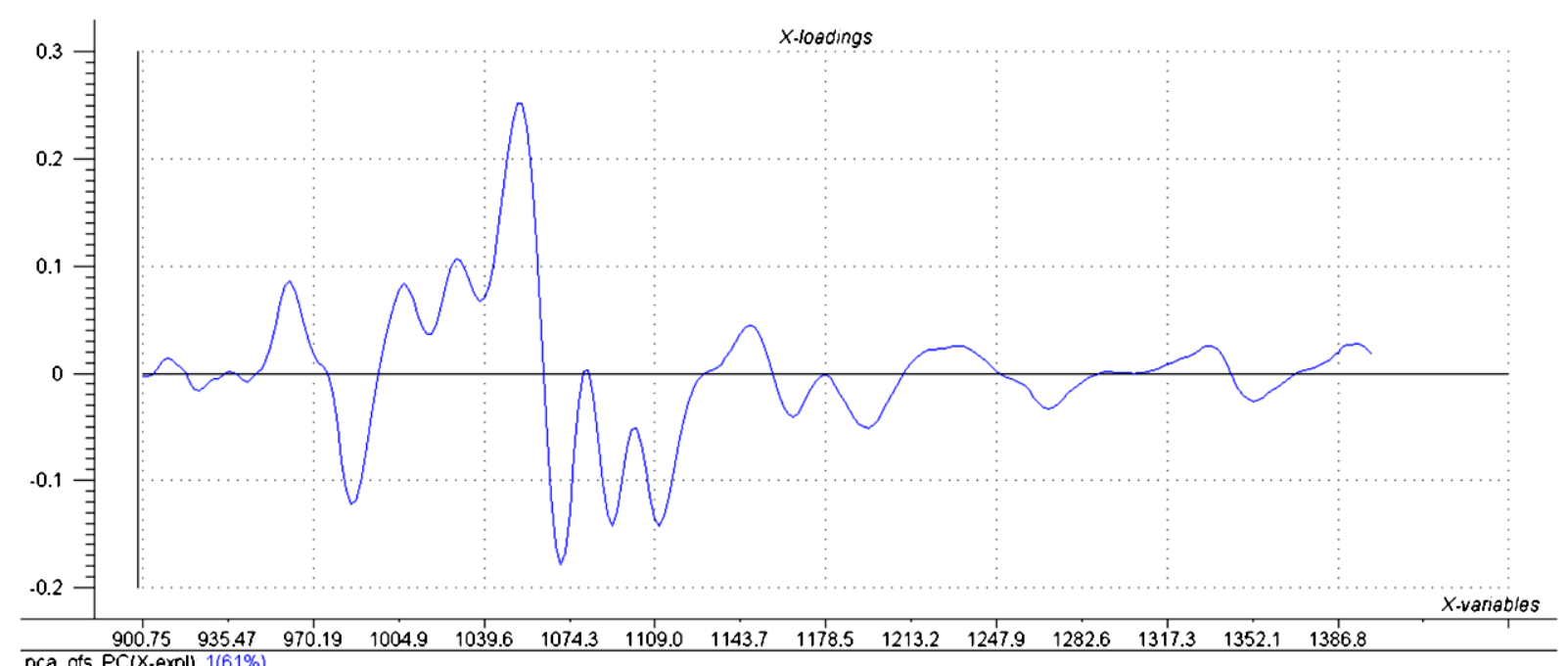

(a)

Fig. 3. Loadings profiles of the first three principal components: PC1 (a), PC2 (b) and PC3 (c), obtained using the first derivative FTIR spectra of the set of 13 standard carbohydrate solutions. (Colors are visible in the online version of the article; http://dx.doi.org/10.3233/SPE-2011-0529.)

carbohydrate solutions at maximum concentration levels are located at the vertexes of the triangle: fructose is located in the positive side of PC1 axis, while sucrose and glucose are located in the negative side of PC1. This distinction can be further interpreted by inspecting the loadings corresponding to PC1 (Fig. 3a) [8]. It can be seen that the shape of PC1 (Fig. 3a) is very close to the first derivative spectrum of fructose (Fig. 1b). 


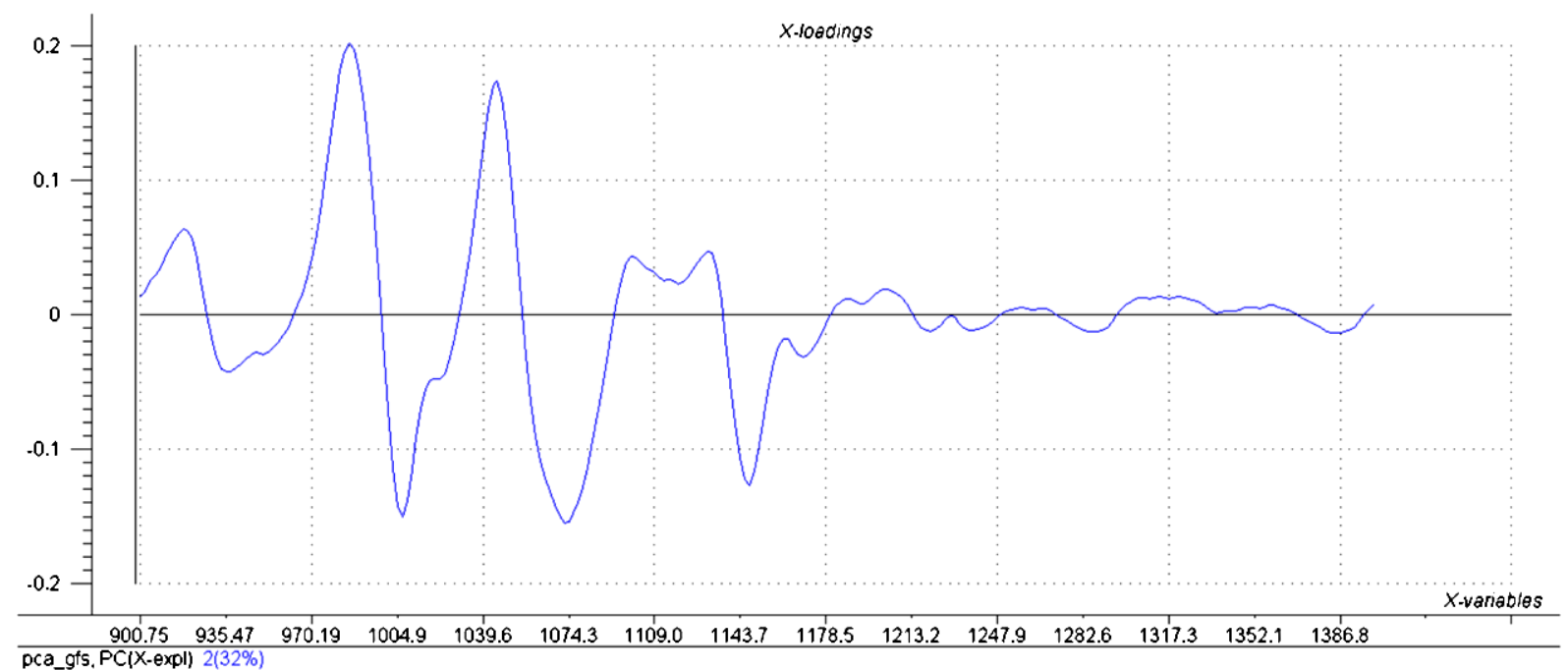

(b)

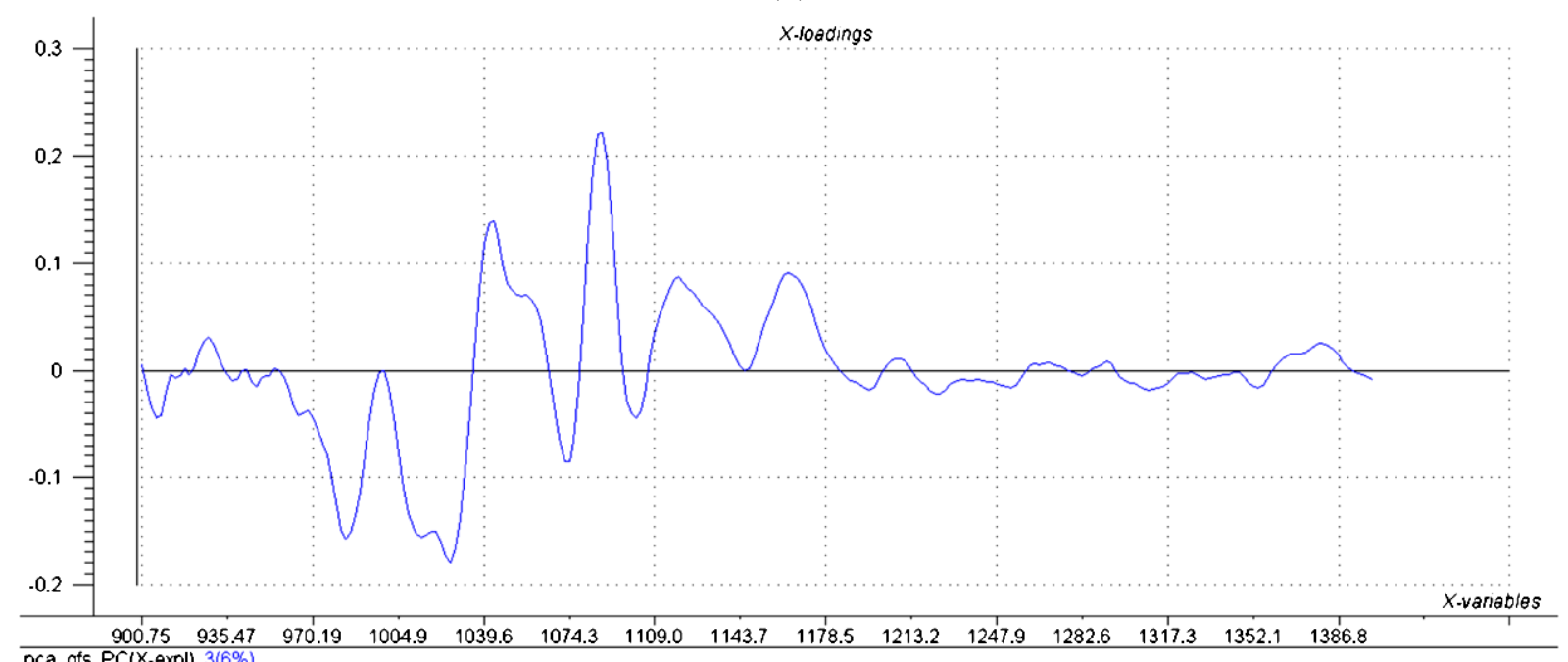

(c)

Fig. 3. (Continued.)

Bands related to fructose are present at $960,1007,1028$ and $1053 \mathrm{~cm}^{-1}$ in the positive PC1 loadings, and at 1070, 1091, $1111 \mathrm{~cm}^{-1}$ in the negative PC1 loadings. Comparison with the first derivative spectrum shown in Fig. 1b confirms that these are indeed the main characteristic bands of fructose. The contributions of glucose and sucrose to $\mathrm{PC} 1$ are much lower as the contribution of fructose.

The loadings plot along the PC2 axis (Fig. 3b) shows a high similitude to the first derivative spectrum of sucrose (Fig. 1b), but contributions from the first derivative glucose spectrum can be also observed. In the positive PC2 loadings region, bands of the first derivative spectrum of sucrose are observed at 985, 1045,1099 and $1130 \mathrm{~cm}^{-1}$, whereas the negative bands at 1007, 1022, 1072 and $1148 \mathrm{~cm}^{-1}$ contribute to the negative loadings. Fructose has a minor contribution to PC2, as also shown in Fig. 2, however, the contribution of glucose cannot be neglected, especially due to the bands at 1007, 1045, 1072 and $1085 \mathrm{~cm}^{-1}$. 


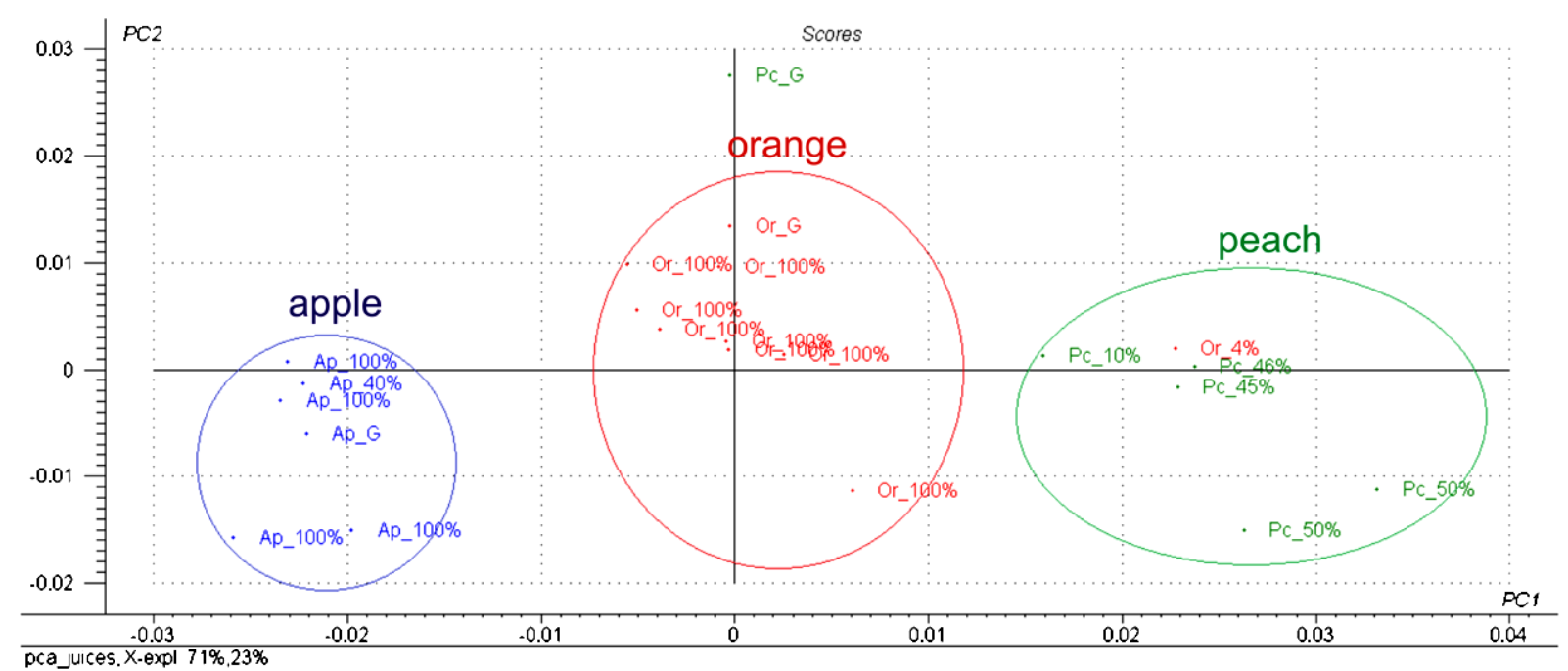

Fig. 4. Scores plot of the first two principal components, PC1 and PC2, obtained from the PCA of the apple, orange and peach juices (genuine and commercial). (Colors are visible in the online version of the article; http://dx.doi.org/10.3233/SPE2011-0529.)

The loadings plot on the PC3 axis (Fig. 3c) shows that glucose has a major contribution to PC3. Glucose has negative contribution on the PC3 axis in the scores plot (not shown here). Thus, positive glucose bands from the first derivative spectrum (Fig. 1b) appear as negative loadings on PC3 (985, 1012,1026 and $1074 \mathrm{~cm}^{-1}$ ), whereas negative glucose bands appear as positive loadings $(1043,1058$ and $1088 \mathrm{~cm}^{-1}$ ).

The potential of FTIR spectroscopy combined with PCA to discriminate between different types of fruit juices is evaluated. Figure 4 shows the scores plot of PC1 and PC2 obtained after the PCA applied to the FTIR spectra of apple, orange and peach juices. The first two PCs of the PCA performed on the FTIR data explain $94 \%$ of the variance in the spectra.

Only the apple, orange and peach juice samples were introduced in the PCA shown in Fig. 4. A grouping of the pear and pineapple juices by PCA was unsuccessfully, variations in pure fruit juice content having a high influence on the grouping. This influence can be also observed in the PCA of the juice samples in Fig. 4, e.g. the juice with $4 \%$ orange fruit content was positioned in the peach juice region, whereas the genuine peach juice appears as an outlier. However, a satisfactory grouping of most apple, orange and peach juices was achieved, in spite of variations in total pure fruit juice content.

\subsection{Partial least squares $(P L S)$ regression}

In order to find the model with best predictive capacity, PLS regression was applied to the raw spectra, to the first derivative spectra, and to the second derivative spectra of the 13 carbohydrate standard mixtures. Table 2 shows the statistical parameters: number of used of principal components (PCs), root mean square error of prediction (RMSEP), root mean square error of calibration (RMSEC) and correlation.

The lower RMSEP values (Table 2) suggest that the best results are provided by the first derivative spectra. Also, first derivative spectra enhance the spectral differences between similar compounds and eliminate baseline drift effects [26]. Thus, the PLS-FTIR model using the first derivative spectra is able to predict carbohydrate contents in fruit juices with lowest prediction errors, as shown in Table 2. 
Table 2

Statistical results (PCs, RMSEC, RMSEP and Correlation) of the application of PLS to the three sets of data: raw spectra, first derivative spectra and second derivative spectra of carbohydrate standard mixtures

\begin{tabular}{lcccc}
\hline Type of spectra & No. of PCs & RMSEC $(\mathrm{g} / 100 \mathrm{ml})$ & RMSEP $(\mathrm{g} / 100 \mathrm{ml})$ & Correlation (R) \\
\hline $\begin{array}{l}\text { Raw spectra } \\
\text { Glucose }\end{array}$ & 3 & 0.077 & & \\
$\quad$ Fructose & 4 & 0.102 & 0.106 & 0.997084 \\
$\quad$ Sucrose & 3 & 0.057 & 0.251 & 0.999643 \\
First derivative spectra & & & & 0.999625 \\
$\quad$ Glucose & 5 & 0.009 & 0.070 & \\
$\quad$ Fructose & 3 & 0.128 & 0.227 & 0.999956 \\
$\quad$ Sucrose & 3 & 0.062 & 0.089 & 0.999436 \\
Second derivative spectra & & & & \\
$\quad$ Glucose & 5 & 0.011 & 0.248 & 0.9999937 \\
$\quad$ Fructose & 3 & 0.103 & 0.245 & 0.999633 \\
Sucrose & 4 & 0.058 & 0.209 & 0.999620 \\
\hline
\end{tabular}

To avoid overfitting, the number of principal components (PCs) is determined by the range in which the explained validation variance increases. Thus, the regression model with the best predictive capacity for glucose concentration used the first five PCs. The percentage of variance in glucose concentration explained by the model was $99.6 \%$.

The regression model for fructose yielded satisfactory results. This model used only three, a lower number of PCs (Table 2), in order to obtain a minimum in the error of prediction (RMSEP). This model describes $99.7 \%$ of the variance in the fructose concentration.

Similarly, by using a model with three PCs the explained validation variance for sucrose was found to be $99.8 \%$.

Thus, based on the optimized regression models described above, Table 3 shows the predicted concentrations for glucose, fructose and sucrose in the commercial and genuine fruit juices. The number of PCs used in the prediction was the same as that determined in the regression models (Table 2). A number of 12 juice samples were selected aleatory and analysed by HPLC, the obtained glucose, fructose and sucrose values being also shown in Table 3 .

Comparing the values of the predicted and HPLC measured carbohydrate concentrations in the fruit juice samples, correlations of $0.88,0.92$ and 0.98 were found for glucose, fructose and sucrose, respectively.

The $100 \%$ fruit labelled apple juice samples show expected values of glucose, fructose and sucrose. For authentic apple juice, an approximate ratio between glucose, fructose and sucrose of 3:6:2 is reported, whereas carbohydrates range from 1-4 (glucose), 5-8 (fructose) and 0 to $5 \mathrm{~g} / 100 \mathrm{ml}$ (sucrose) [15].

Raw oranges have a medium glucose, fructose and sucrose content of $2.2-2.4,2.5-3$ and 4 $4.8 \mathrm{~g} / 100 \mathrm{ml}$, respectively $[9,27]$. It can be seen that the predicted values $(2.44,2.49,4.01 \mathrm{~g} / 100 \mathrm{ml})$ for the genuine, squeezed orange juice are in good concordance with the above mentioned medium ranges. The samples, Or8_100\% and Or9_4\% show considerable deviations from the mean values. It can be also seen in the PCA analysis that the Or8_100\% sample (positioned in Figure 4 at negative PC2 values) shows a considerable deviation from the other orange juice samples. The orange juice labelled $4 \%$ fruit (Or9_4\%) shows a sucrose concentration $(7.90 \mathrm{~g} / 100 \mathrm{ml})$ of almost two times higher compared 
Table 3

Predicted (FTIR) and measured (HPLC) glucose, fructose and sucrose concentrations (g/100 ml) in commercial and genuine fruit juices

\begin{tabular}{|c|c|c|c|c|c|c|c|}
\hline \multirow[t]{2}{*}{ No. } & \multirow[t]{2}{*}{ Sample } & \multicolumn{2}{|c|}{ Glucose } & \multicolumn{2}{|c|}{ Fructose } & \multicolumn{2}{|c|}{ Sucrose } \\
\hline & & FTIR & HPLC & FTIR & HPLC & FTIR & HPLC \\
\hline 1 & Ap1_100\% & 3.28 & 3.1 & 6.9 & 6.8 & 1.15 & 1.47 \\
\hline 2 & Ap2_100\% & 3.99 & - & 9.92 & - & 1.52 & - \\
\hline 3 & Ap3_100\% & 3.62 & - & 9.33 & - & 2.44 & - \\
\hline 4 & Ap4_100\% & 3.23 & - & 7.62 & - & 1.28 & - \\
\hline 5 & Ap5_40\% & 4.91 & - & 6.32 & - & 1.21 & - \\
\hline 6 & Ap_G & 2.72 & 3.01 & 8.4 & 8.8 & 1.71 & 2.1 \\
\hline 7 & Ac_50\% & 3.96 & 2.85 & 3.08 & 4.42 & 8.88 & 8.84 \\
\hline 8 & $\mathrm{Ch} \_15 \%$ & 8.30 & 6.01 & 7.67 & 10.01 & 2.51 & 2.35 \\
\hline 9 & Or1_100\% & 2.91 & 3.01 & 3.03 & 3.52 & 4.1 & 4.36 \\
\hline 10 & Or2_100\% & 3.84 & - & 3.95 & - & 3.83 & - \\
\hline 11 & Or3_100\% & 3.18 & - & 3.32 & - & 3.31 & - \\
\hline 12 & Or4_100\% & 3.62 & - & 3.84 & - & 4.96 & - \\
\hline 13 & Or5_100\% & 3.78 & - & 3.97 & - & 4.49 & - \\
\hline 14 & Or6_100\% & 3.65 & - & 3.83 & - & 3.57 & - \\
\hline 15 & Or7_100\% & 3.72 & - & 3.87 & - & 4.43 & - \\
\hline 16 & Or8_100\% & 5.08 & - & 5.14 & - & 6.05 & - \\
\hline 17 & Or9_4\% & 2.35 & - & 2.3 & - & 8.12 & - \\
\hline 18 & Or_G & 2.44 & 2.19 & 2.49 & 2.21 & 4.01 & 4.47 \\
\hline 19 & Pc1_50\% & 3.50 & - & 3.07 & - & 10.28 & - \\
\hline 20 & Pc2_50\% & 4.48 & - & 4 & - & 9.34 & - \\
\hline 21 & Pc3_46\% & 2.49 & - & 2.4 & - & 8.32 & - \\
\hline 22 & Pc4_45\% & 3.02 & 2.1 & 2.64 & 3.7 & 8.28 & 8.21 \\
\hline 23 & Pc5_10\% & 2.88 & - & 2.89 & - & 7.09 & - \\
\hline 24 & Pc_G & 0.66 & 0.75 & 0.71 & 1 & 3.4 & 3.6 \\
\hline 25 & Pi1_100\% & 5.20 & 3.21 & 4.6 & 5.89 & 6.61 & 6.01 \\
\hline 26 & Pi2_50\% & 4.93 & - & 4.6 & - & 3.74 & - \\
\hline 27 & Pi_G & 2.33 & 2.4 & 2.51 & 2.6 & 5.45 & 5.33 \\
\hline 28 & Pr1_50\% & 2.48 & 1.88 & 3.85 & 3.98 & 7.71 & 8.45 \\
\hline 29 & Pr2_50\% & 2.71 & - & 4.34 & - & 4.31 & - \\
\hline 30 & Pr3_50\% & 2.86 & - & 4.87 & - & 8.35 & - \\
\hline 31 & Pr4_30\% & 2.26 & - & 7.95 & - & 6.52 & - \\
\hline 32 & Pr_G & 3.19 & 2.63 & 9.49 & 8.82 & 1.18 & 1.44 \\
\hline 33 & To_100\% & 1.98 & - & 1.78 & - & 0.15 & - \\
\hline
\end{tabular}

to the other orange juices, probably due to the addition of supplementary sucrose, necessary to maintain the sweetness intensity.

Pure peach juice is characterized by a high sucrose content of approximate $5.5 \mathrm{~g} / 100 \mathrm{ml}$ and lower glucose and fructose contents, of 1.1 and $1.3 \mathrm{~g} / 100 \mathrm{ml}$, respectively [9,27]. Glucose and fructose concentrations below the above mentioned values were predicted for the genuine peach juice. The lower values can be due to a harvest at a different ripening stage as the fruits processed to commercial juices.

Ripe mature pineapple flesh juice contains about $7 \mathrm{~g} / 100 \mathrm{ml}$ sucrose and $3 \mathrm{~g} / 100 \mathrm{ml}$ each of glucose and fructose [14]. An expected sucrose content was predicted for the genuine pineapple and Pi1_100\% juice samples, whereas the $50 \%$ fruit pineapple juice shows only $3.74 \mathrm{~g} / 100 \mathrm{ml}$ sucrose. 
Authentic pear juice is characterized by a high fructose and low sucrose content [9,27]. The genuine pear juice shows concentrations of 9.49 and $1.18 \mathrm{~g} / 100 \mathrm{ml}$ for fructose and sucrose, respectively. Therefore, due to the high sucrose content $(4.31-8.35 \mathrm{~g} / 100 \mathrm{ml})$ predicted for the commercial pear juice samples, the addition of sweeteners is supposed.

Finally, a $100 \%$ tomatoes vegetable juice was also analyzed. The predicted values of glucose and sucrose are in good concordance with literature values [9,27], the lack of sucrose in tomatoes is shown also by the predicted value. Also, a total predicted carbohydrate content of $3.76 \mathrm{~g} / 100 \mathrm{ml}$ is in good agreement with the labelled value of $3.5 \mathrm{~g} / 100 \mathrm{ml}$.

\section{Conclusions}

FTIR spectroscopy and multivariate statistics (PCA and PLS) enabled reliable evaluation of fruit juice quality. The first derivative FTIR spectra were found to exhibit the best predictive capacity, due to low RMSEP values. PCA analysis of the standard carbohydrate solutions enabled a better understanding of the main sources of variability affecting the FTIR spectra, whereas PCA of the fruit juices FTIR spectra enabled the grouping of apple, orange and peach juices. A satisfactory correlation between carbohydrate predicted data, using FTIR spectroscopy, and HPLC reference values was found. Overall, the present results suggest that FTIR spectroscopy, in combination with multivariate statistics, represents a rapid, reliable and cost-effective tool for routine monitoring of multiple constituents in fruit juices, as quality indicators.

\section{Acknowledgements}

Financial support from the EU-FP6-Project COLL-CT-2005-012461, Qualijuice, is highly acknowledged. Support from CNCS-UEFISCDI, project number PN II-RU TE_323/2010 is highly acknowledged by N. Leopold.

\section{References}

[1] V. Bellon-Maurel, C. Vallat and D. Goffinet, Appl. Spectrosc. 49 (1995), 556.

[2] F. Cadet, Talanta 48 (1999), 867.

[3] F. Cadet and B. Offmann, J. Agric. Food Chem. 45 (1997), 166.

[4] T.R.I. Cataldi, G. Margiotta and C.G. Zambonin, Food Chem. 62 (1998), 109.

[5] M.A. Coimbra, A. Barros, D.N. Rutledge and I. Delgadillo, Carbohydr. Res. 317 (1999), 145.

[6] C. Corradini, G. Canali and I. Nicoletti, Semin. Food Anal. 2 (1997), 99.

[7] M. Defernez and R.H. Wilson, J. Sci. Food Agric. 67 (1995), 461.

[8] I.F. Duarte, A. Barros, I. Delgadillo, C. Almeida and A.M. Gil, J. Agric. Food Chem. 50 (2002), 3104.

[9] M.E. Ensminger and A.H. Ensminger, Foods and Nutrion Encyclopedia, CRC Press, Boca Raton, FL, 1997.

[10] K.H. Esbensen, D. Guyot, F. Westad and L.P. Houmøller, Multivariate Data Analysis: In Practice, Camo Process AS, Oslo, 2002.

[11] S. Garrigues, F.J. Rambla and M. De La Guardia, Fresenius J. Anal. Chem. 362 (1998), 137.

[12] P. Geladi and B.R. Kowalski, Anal. Chim. Acta 185 (1986), 1.

[13] J. He, L.E. Rodriguez-Saona and M.M. Giusti, J. Agric. Food Chem. 55 (2007), 4443.

[14] Y.H. Hui, Handbook of Food Products Manufacturing, Wiley, Hoboken, NJ, 2007.

[15] J. Irudayaraj and J. Tewari, Appl. Spectrosc. 57 (2003), 1599.

[16] M. Kačuráková and R.H. Wilson, Carbohydr. Polym. 44 (2001), 291.

[17] R. Kellner, B. Lendl, I. Wells and P.J. Worsfold, Appl. Spectrosc. 51 (1997), 227. 
[18] J.F.D. Kelly and G. Downey, J. Agric. Food Chem. 53 (2005), 3281-3286.

[19] J.F.D. Kelly, G. Downey and V. Fouratier, J. Agric. Food Chem. 52 (2004), 33.

[20] E.K. Kemsley, J.K. Holland, M. Defernez and R.H. Wilson, J. Agric. Food Chem. 44 (1996), 3864.

[21] E.K. Kemsley, R.H. Wilson, G. Poulter and L.L. Day, Appl. Spectrosc. 47 (1993), 1651.

[22] W. Kessler, Multivariate Datenanalyse für die Pharma-, Bio- und Prozessanalytik, Wiley, Weinheim, 2006.

[23] L.F. Leopold, N. Leopold, H.A. Diehl and C. Socaciu, J. Food Anal. Methods (2011), 1-3, available at: http://www. springerlink.com/content/e22618762443k212/, http://dx.doi.org/10.1007/s12161-011-9251-z (published Online First ${ }^{\mathrm{TM}}$, 6 June 2011).

[24] G.G. Pan, P.A. Kilmartin, B.G. Smith and L.D. Melton, J. Sci. Food Agric. 82 (2002), 421.

[25] M.D. Queji, G. Wosiacki, G.A. Cordeiro, P.G. Peralta-Zamora and N. Nagata, Int. J. Food Sci. Tech. 45 (2010), 602.

[26] F.J. Rambla, S. Garrigues, N. Ferrer and M. De La Guardia, Analyst 123 (1998), 277.

[27] US Department of Agriculture, Agricultural Research Service, USDA National Nutrient Database for Standard Reference, Release 22, Nutrient Data Laboratory Home Page, 2009, available at: http://www.ars.usda.gov/ba/bhnrc/ndl.

[28] R.H. Wilson and H.S. Tapp, Trends Anal. Chem. 18 (1999), 85. 


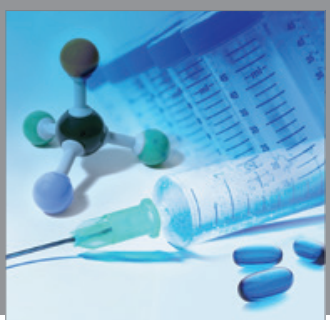

International Journal of

Medicinal Chemistry

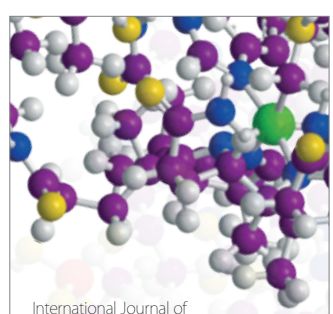

Carbohydrate Chemistry

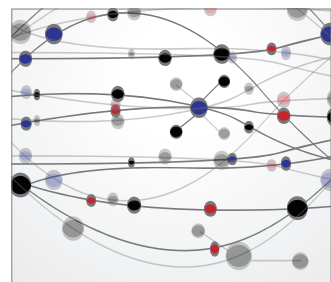

The Scientific World Journal
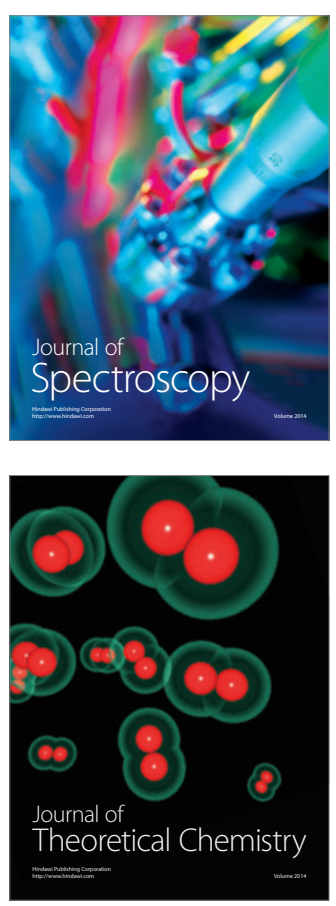
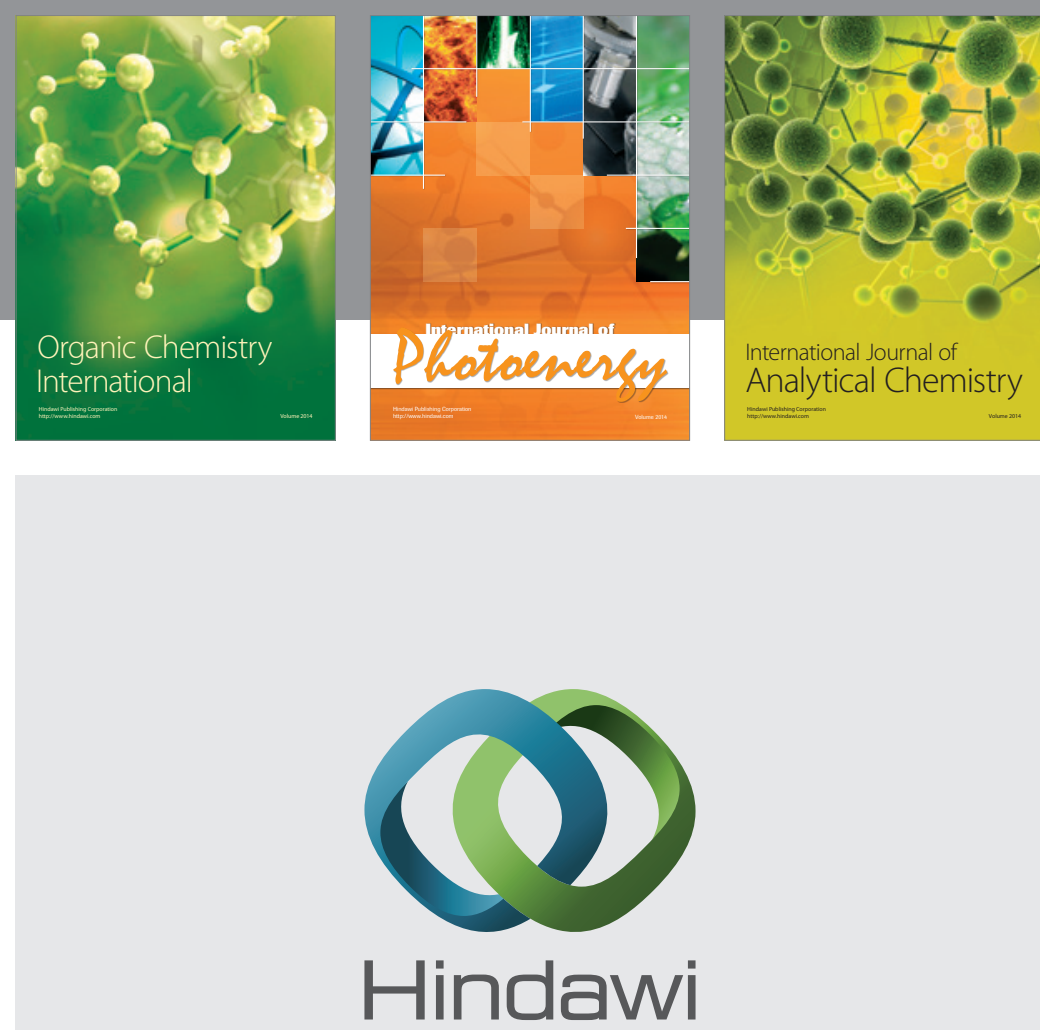

Submit your manuscripts at

http://www.hindawi.com
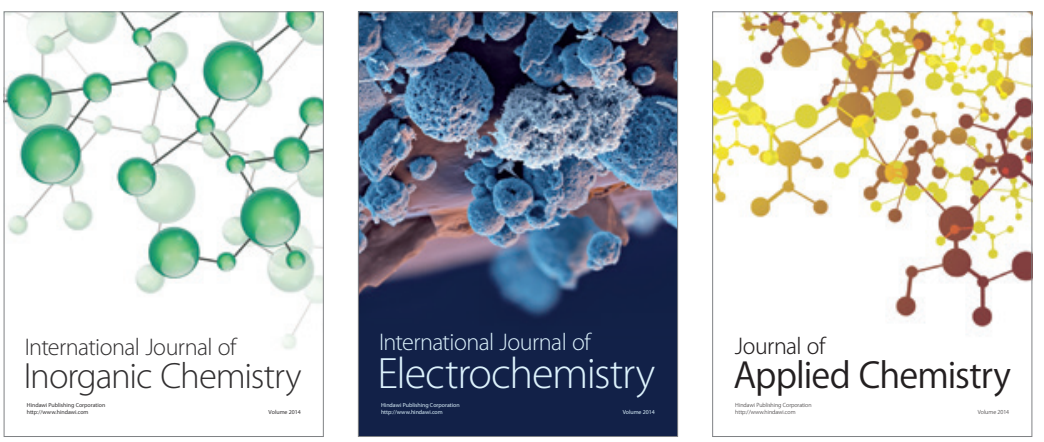

Journal of

Applied Chemistry
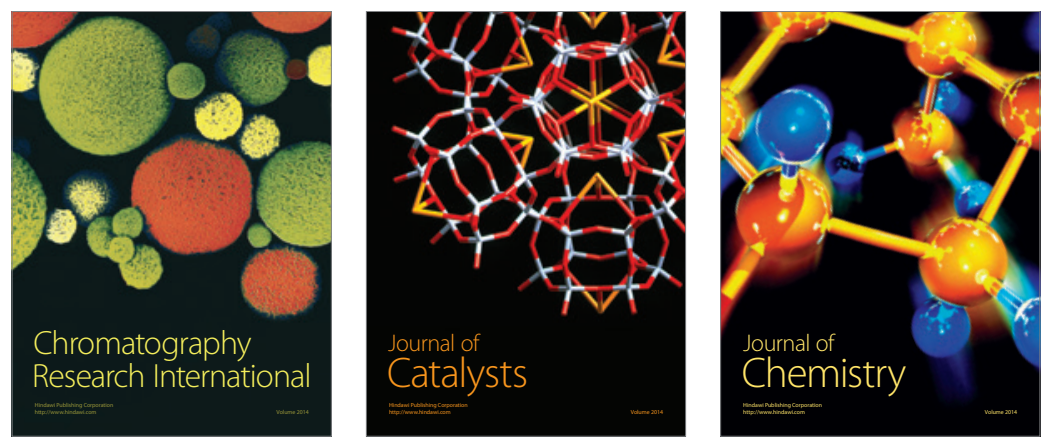
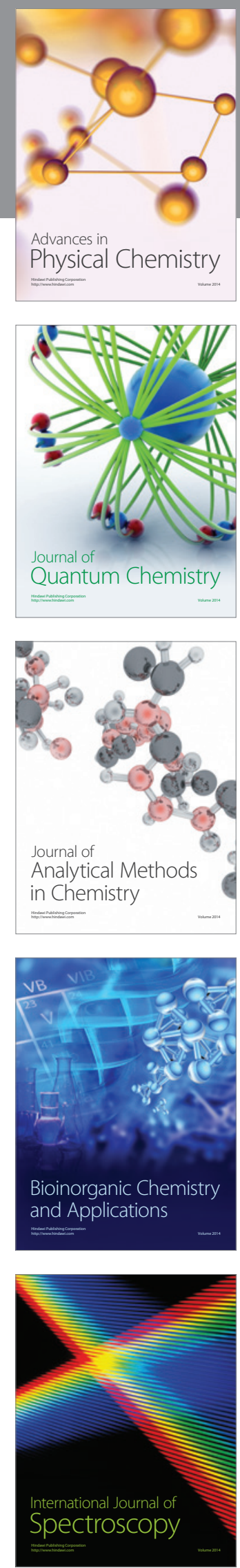